\title{
El lenguaje del atún, una creación sociocultural mediterránea
}

\section{The Tuna Lexicon, a Mediterranean Sociocultural Creation}

\author{
Francesc Xavier Llorca Ibi ${ }^{1}$ \\ Facultad de Educación, Universidad de Alicante
}

\section{RESUMEN}

El lenguaje del atún es un argot creado por el conjunto de profesionales que intervienen en las labores de captura y procesamiento de los túnidos. Este grupo sociolaboral, formado por comunidades humildes, ha sido históricamente discriminado por el resto de los estamentos sociales, factor que ayudó a la construcción de un léxico particular. A esto hay que añadir que, en el repertorio de voces almadraberas, hubo una importante contribución de grupos migrantes de pescadores de lenguas diversas, otro hecho que marcó la singularidad de estos profesionales frente a otros hablantes. Así pues, el estudio de los términos que forman este lenguaje, como también su contexto social e histórico, nos permitirá visualizar las relaciones de cooperación e intervención cultural, tecnológica, económica y lingüística que unas comunidades realizaron sobre otras dando lugar a un símbolo de la cultura mediterránea, el lenguaje del atún.

Palabras clave: Atún; Almadraba; Lenguaje; Arabismos; Italianismos; Lusismos.

\section{SUMMARY}

The tuna lexicon is a slang created by professionals involved in the process of catching and processing tuna fish. This social work-related group, made up of humble communities, has historically faced discrimination from other social strata, a factor which has contributed to the construction of their own lexicon. Another significant contribution in the configuration of trap-netting words has come from groups of migrant fishermen who speak different languages, which also distinguishes these professionals from other speakers. Thus, the study of the terms that make up this lexicon, and of its social and historical context, will allow us to visualize the relationships of cooperation and cultural, technological, economic and linguistic intervention made by some communities in others, making the tuna lexicon a symbol of Mediterranean culture.

Key words: Tuna Fish; Trap Netting; Lexicon; Arabic Expressions; Italianisms; Portuguese Expressions.

\section{INTRODUCCIÓN}

El atún es la especie Thunnus thynnus —atún rojo- que junto a Thunnus albacares — rabil—, Thunnus alalunga —albacora o atún blanco-, Thunnus obesus

\footnotetext{
${ }^{1}$ Correo electrónico: francesc.llorca@ua.es. ORCID ID: http://orcid.org/0000-0001-7633-3133.
} 
—atún patudo-, Euthynnus alleteratus — bacoreta-, Katsuwonus pelamis —listado-, Sarda sarda - bonito- y Auxis rochei - melva-, entre otros, forman la familia de los Thunnidae.

La industria del atún (captura, tratamiento y comercialización de túnidos) fue realizada con la participación de comunidades itinerantes de pescadores a través de unas rutas que unían el Mediterráneo y el Atlántico inmediato provocando unas profundas interacciones tecnológicas y culturales. De este proceso se tiene constancia desde que los fenicios exportaran hacia oriente los productos de las atunaras hispánicas; un tipo de transacciones comerciales que llegan hasta nuestros días en las que los atunes son directamente enviados a Japón desde aguas gaditanas.

Estas relaciones han tenido un reflejo muy importante en la lengua de las comunidades que participan de los procesos haliéuticos, comerciales y gastronómicos, dando lugar a un conjunto de términos privativos usados por los profesionales de la pesca y procesamiento de los túnidos que hemos denominado lenguaje del atún. Este argot ha sido considerado secularmente un habla distintiva por otros hablantes como podemos deducir de la expresión "en aquel lenguaje que usan los pescadores" en este texto del siglo XVI:

Llevan estos [los almadraberos] muy grandes garauatos de hierro, asidos y muy bien clavados a vnas varas de media vara, a los quales garauatos llaman cloques en aquel lenguaje que usan los pescadores $[\ldots]^{2}$.

Es un habla fundamentada en un vocabulario de gran riqueza y complejidad no solo por tratarse de un léxico profesional sino también por la diversidad de personas y lenguas que se imbrican en los distintos procesos de esta industria, dando lugar a unas características distintivas del lenguaje del atún que se concretan en dos puntos principales: la singularidad sociolaboral de las comunidades almadraberas y el alto grado de mestizaje léxico.

La particularidad de las comunidades almadraberas como grupo históricamente marginado por los estamentos urbanos y rurales es fundamental para entender el lenguaje del atún. Tengamos presente que los pescadores habitaban los extrarradios geográficos y sociales acentuando la visión negativa de sus conciudadanos. La afirmación del padre jesuita Juan de Santibáñez sobre el paisaje humano de la atunara de Zahara en el siglo XVI es una muestra significativa donde se describen estratos sociales cuasi marginales y de origen foráneo comunes a los lugares de establecimiento de las pesquerías:

Júntase aquí [en la almadraba] de varías partes de la Andalucía y hasta de los más remotos lugares de Castilla, Aragón, Cataluña, Portugal y Galicia gran número de ventureros y hombres perdidos, muchos dellos facinerosos, rufianes y forajidos. Estos traen consigo mugercillas infames ${ }^{3}$.

Una realidad particular que, junto al alejamiento físico de los otros estamentos, ayudó a crear más identidad diferenciada y cohesión dentro de los pescadores del atún como explica Florido (2003: 4):

\footnotetext{
${ }^{2}$ Pérez de Messa (1595, II, cap. VIII, fol. 107-108), en Florido (2005: 15-16).

3 P. Juan de Santibáñez, s/d: Historia de provincia de Andalucía de la Compañía de Jesús, ms. en Florido (2005: 34).
} 
Así, hemos de destacar este aspecto, menos evidente, más difícil de valorar socialmente, pero que consideramos igualmente importante del modelo de producción espacial de las almadrabas y de su impronta territorial: la segregatividad; esto es la conformación de núcleos de trabajo y poblamiento apartados, en cierto modo encerrados en sí mismos y caracterizados por duras condiciones de vida y todo un conjunto de caracterizaciones sociales externas que inciden en la marginalidad, no ya espacial, sino plenamente social.

Todas estas características propiciaron que las almadrabas crearan un universo culturalmente específico (Florido 2005: 3) del cual resultó un lenguaje característico como escribía Guillén Tato (1963: 22):

[...] pero muy especialmente la almadraba, en cuyo mundillo abundan voces y locuciones remotísimas y exclusivas, tal que: arráez*, sotarráez $z^{*}$, acurullador*, almocero*, paralero*, almocaé $n^{*}$, alcanela*, manión ${ }^{*}$, antitola ${ }^{*}$, mascarana $^{*}$, bordonak ${ }^{*}$, mojarra*..., que ningún marino ajeno a esta pesquera puede desentrañar [...].

Y, dentro del mundo almadrabero, los vocablos de las actividades relacionadas con el atún llegarán a constituir un léxico aún más particularizante. Bellón (1926: 96-97) era consciente de esta singularidad léxica y el mestizaje del lenguaje atunero:

Les différentes parties de l'animal reçoivent des noms spéciaux, généralement des corruptions de mots italiennes et portugaises.

Por tanto, estamos ante un habla con características propias de grupo profesional, más marcado aún por una serie de términos de variedades diatópicas y diastráticas alejadas del lenguaje general.

En el sentido lingüístico y social son reveladores los sustantivos usados en el siglo XVI para definir al colectivo de servidores de la almadraba como chusma o ventureros, cargados ambos de fuertes connotaciones negativas. De hecho, en los contratos del siglo XVII, que tuvieron que ser suavizados por la falta de personal, se sustituye el despectivo venturero por el neutro paralero para designar a los mozos que halaban las sirgas (Florido 2005: 30). Una marginalidad que contrasta con la avidez con que la población buscaba los productos que allí se producían, y que fue origen de la expansión lingüística de ciertos términos almadraberos por otros estratos sociales. Unos vocablos argóticos expandidos por la necesidad alimenticia y la cultura gastronómica.

Pero aunque la terminología del atún tiene una larga tradición en castellano y en las otras lenguas mediterráneas, su léxico ha sido estudiado de manera parcial y dispersa. Los estudios estrictamente lingüísticos sobre el tema son escasos y, generalmente, las referencias léxicas se encuentran incardinadas en textos de otros aspectos como el histórico, económico, biológico y gastronómico.

De los trabajos específicos sobre el lenguaje de las almadrabas podemos indicar La saladura $i$ els seus noms de Maria Antònia Cano (1993), Xanca, Chanca: un italianisme del català $i$ de l'espanyol (2004) y Llengua d'arraix. La parla almadravera valenciana (2008) de Francesc Xavier Llorca, Il lessico storico delle tonnare: Alcune riflessioni de Fiorenzo Toso (2012a) y Mattanza de Fiorenzo Toso (2012b). Sí que encontramos diversos estudios, no estrictamente lingüísticos, donde se incluye el léxico del atún como el Diccionario de los artes de la pesca nacional de Antonio Sáñez (1791), Il tonno e la sua pesca de Corrado Parona (1919), Diccionario de artes de pesca de España y sus posesiones de Benigno Rodríguez (1923), La industria del atún en 
España de Luis Bellón (1926), Almadrabas de la costa alicantina de Manuel Oliver (1982), A pesca do atum no Algarve de Luís Filipe Rosa (1989), El pan y los peces. Santi Petri en la memoria de Miguel Ángel García (2001) y La almadraba de Nueva Umbría de Juan Manuel Ruiz y José Antonio López (2005). Asimismo son indispensables las monografías La salazón de pescado, una tradición en la dieta mediterránea de Lorena Gallart et al. (2005), obra muy valiosa para el estudio lingüístico, aunque no sea su principal objetivo; y El atún y la alimentación mediterránea de José Antonio López et al. (2007), que aporta una excelente información lingüística a partir de aspectos varios del atún. En el contexto sociocultural hay que resaltar los trabajos de David Florido La almadraba como sistema cultural de pesca (2003) y Evolución histórica y cultural de las almadrabas en el litoral atlántico meridional (siglos XVI-XX) (2005). En referencia al aspecto gastronómico relacionado con la terminología atunera son destacables Almadraba, salazón y cocina de Carlos Llorca y Jorge Norberto (1988) y A tutto tonno de Carmelo Chiaramonte (2006).

Por tanto, como objetivos principales de este estudio tendremos, en primer lugar, cubrir la laguna existente en la recopilación sistemática de los vocablos referidos a la industria del atún; y, en segundo lugar, estudiar esta terminología como muestra de creación cultural antropológica fruto de la interacción entre diversas comunidades humanas y lingüísticas que nos permitan conocer cómo se ha formado su lenguaje. A su vez, el estudio léxico nos orientará sobre las relaciones de cooperación e intervención entre estos grupos. Todo ello redundará en un mayor conocimiento sociocultural del Mediterráneo desde los orígenes hasta la actualidad.

Para poder recopilar el léxico del atún y de los procesos de conservación hemos entrevistado a profesionales de su pesca en el Mediterráneo y el Atlántico, especialmente almadraberos. Entre estas personas debemos destacar a los arráeces, todos naturales de Benidorm - excepto el señor Columé de Isla Cristina-, que son por orden alfabético: Claudio Columé Feria (Cabo Espartel, Cenisoso, Punta Negra y Kenitra); José Llorca Zaragoza (Agadir); Jaime Pérez Zaragoza (Tánger); Miguel Soldevila Lloret (Benidorm) y Jacinto Vaello Llorca (Las Cabezas, La Umbría, La Tunara, Santi Petri y Tarifa). Asimismo, fueron destacados informantes Antonio Agulló Cortés, propietario y patrón de la almadrabeta "llissera" de Benidorm; José Ribes Buigues, patrón y propietario de la almadraba de Jávea; Juan Santacreu Luchoro propietario y patrón de la almadrabeta moruna de Isla de Tabarca; y José Zaragoza Pérez, varilla, tercero y sotarráez en diversas almadrabas como Tánger, Barbate, Larache y Arcila.

También se entrevistó a marineros de diversas atunaras como Enrique Aldeguer Luchoro (Villajoyosa), Lluís Brull i Núñez (L’Ametlla de Mar), Joan Cano Fuster (Benidorm), Josep Llinares Martínez (Kenitra), Miguel Llorca Lloret (Villajoyosa), Rafael Orquín Bernabeu (Túnez), Jaime Robles Mayor (Cope), Quico Serrat Pérez (Kenitra y Larache) y Diego Soria Zaragoza (Benidorm). En el campo específico de la salazón destacaremos a Ramón Ronda Lloret, descendiente de una saga centenaria de profesionales que desarrollaron su oficio en Villajoyosa. También se entrevistó a Juan García Palomares, artesano salazonero de El Campello; y, a Andrés Mas Aldeguer de Santa Pola, que trabajó diversas temporadas en la fábrica familiar de Ceuta, abastecida por la almadraba de Carranza. La información fue completada con entrevistas a diversos marineros que han capturado el atún con otros sistemas, vendedores y productores domésticos de salazón (en los dos últimos grupos se incluían informantes femeninos). 
Las entrevistas, siguiendo las directrices del método etnolingüístico, se realizaron a 30 personas, desde 1987 hasta la actualidad. La fecha de nacimiento de los entrevistados se situaba entre 1900 y 1943. Así pues, hemos seleccionado — principalmentepersonas dedicadas profesionalmente a la pesca del atún desde su juventud, incluyendo sagas de arráeces almadraberos. Las respuestas eran recogidas de forma escrita y, mayoritariamente, grabadas. Se requería al informante para que explicara su actividad profesional y era interpelado para aclaraciones sobre ciertos elementos de interés como materiales, técnicas, voces o expresiones singulares. Asimismo se realizaban preguntas directas para ampliar aquellos aspectos más interesantes o los que no se habían entendido claramente.

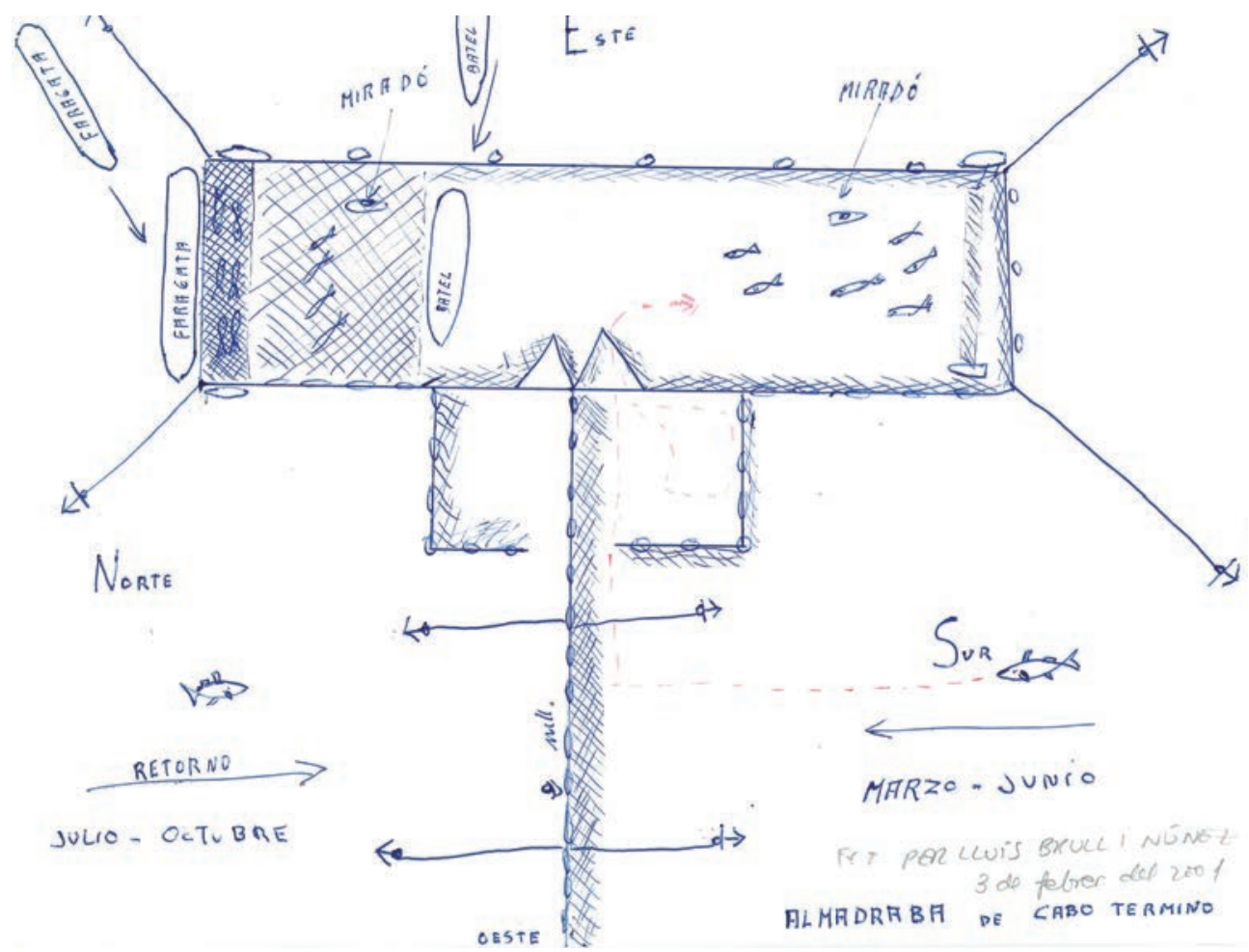

Imagen 1.- Almadraba de Cabo Término (Tarragona). Dibujo realizado por Don Lluís Brull i Núñez durante la entrevista del 3 de febrero de 2001.

En el caso de las almadrabas, los entrevistados poseían multitud de documentos y materiales como maquetas, planos, fotografías —o realizaban dibujos en el momento- para aclarar ciertos aspectos. La relación con los arráeces y almadraberos benidormenses, por amistad familiar y de vecindad, facilitó en todo momento la recogida de información. Además, también se entrevistaron profesionales de la zona geográfica comprendida entre L'Ametlla de Mar (Tarragona) e Isla Cristina (Huelva), con 
la finalidad de obtener la mayor información lingüística oral posible que facilitara el contraste léxico. Asimismo hemos contado con la desinteresada y entusiasta colaboración de José Antonio López González (Isla Cristina), estudioso de la cultura y gastronomía almadraberas, que ha aportado innumerables materiales e informaciones para el conocimiento de la almadraba y del atún atlántico.

Además, este material lingüístico oral ha sido ampliado y contrastado con la bibliografía especializada disponible sobre túnidos, almadraba y salazón, particularmente de Italia y Portugal. Este contraste textual y lingüístico, siguiendo metodología filológica y desechando textos de poco rigor científico, ha permitido obtener un repertorio léxico fehaciente e incardinado en su contexto histórico, social y profesional. Un material que ha facilitado unas conclusiones veraces sobre la formación, expansión y evolución de la lengua del atún con especial referencia a los contactos humanos y lingüísticos que se derivan de su captura, tratamiento y venta por las costas del Mediterráneo y el área atlántica limítrofe.

\section{CONTEXTO HISTÓRICO DE LA PESCA DEL ATÚN}

Las primeras muestras arqueológicas de la captura del atún se encuentran en la cueva del Genovese en Levanzo (Sicilia) donde se constata que el atún se capturaba ya en el Neolítico (Chiaramonte 2006: 11). Asimismo, los primeros habitantes de

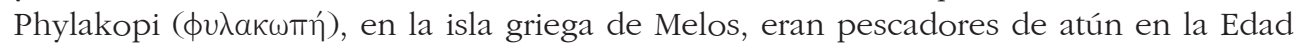
de Bronce, datación que nos permite considerar esta población como uno de los primeros enclaves atuneros de la historia (Abulafia 2013: 36; Opiano 1990: 271), en el siglo II a. C., dejó constancia de la captura de atunes por todas las etnias mediterráneas:

Primero, dentro del mar Ibérico, los capturan los íberos, que están orgullosos de su fuerza; después, cerca de la desembocadura del Ródano, los pescan los celtas y los antiguos habitantes de Focea. Y en tercer lugar, aquellos que moran en la isla Trinacria y cerca de las olas del mar Tirreno. Desde allí, en las inmensas profundidades, se esparcen por diversos caminos y recorren todo el mar.

Una captura muy deseada por el valor gastronómico y pecuniario que tenían los productos derivados, especialmente salados como el clásico garum y que nos hace comprender la importancia y la perdurabilidad de los lazos comerciales lejanos desde que fenicios, griegos y púnicos iniciaron el trasiego de tan valiosa mercancía (Oliver 1982: 47-88; Mederos 2007; Ruiz y López 2005: 18-23). De hecho este pez fue uno de los iconos preferidos por los fenicios para grabar sus monedas, desde el siglo III a. C. en Cádiz, muestra fehaciente de su relevancia económica y simbólica (Mederos 2007: 173-174). Un negocio pujante que los mercaderes romanos llevaron hasta la desembocadura del Rin (Gallart et al. 2005: 36). Comercio que se vio afectado por la desintegración del Imperio romano pero que resurgió con el dominio musulmán del Mare Nostrum. Posteriormente, con la conquista de al-Ándalus por los reinos cristianos, los establecimientos atuneros aumentaron su importancia y se convirtieron en centros económicos y poblacionales de primer orden como expone Rosa (1989: 20) de Portugal: 
Uma data importante para o Algarve, mas principalmente para a vila de Lagos, foi o ano de 1502, quando o rei D. Manuel I ordenou a criação nesta vila, do que terá sido, segundo Romero Magalhães, o organismo mais importante da administração régia no sul do país - A feitoria das almadravas. Tal seria a importância, que a pesca do atum economicamente detinha para o país e o papel que Lagos representava no escoamento do produto!

Más tarde, en las décadas centrales del siglo XVI, llegó la época dorada de las pesquerías con centros almadraberos fundamentales como Conil y Zahara. Un tiempo de prosperidad que, a partir del último tercio de ese siglo, se torna en decadencia en las costas de Andalucía hasta finales del XVIII (Florido 2005: 12-13). Por otro lado, fue en este período de retraimiento de las almadrabas andaluzas, donde aparece un nuevo ingenio para la pesca del atún en el Reino de Valencia, la almadraba de buche. Este nuevo artilugio fue calado por expertos sicilianos como consta en el documento titulado Privilegi Real fachendi en favor del Magnifich Hierony Salvador menor sobre la peysca de tonyines en les mars del present Regne, firmado en el monasterio de San Lorenzo de El Escorial el 19 de junio de 1577. El privilegio concedido a Jerónimo Salvador fue ampliado para los mares de Cataluña, Rosellón y Cerdeña al año siguiente (Oliver 1982: 111). Un nuevo ingenio que permitió la especialización de los marineros de Benidorm, cantera histórica de arráeces, en el calamento del arte como señalaba Cavanilles (1795, II, 242) en 1797:

Fuera de la agricultura tienen los de Benidórm una fuente de riquezas en el mar. Ocupados de tiempo inmemorial en la pesca del atún, conocen á fondo las maniobras de tender las almadrabas ó redes para coger mas atunes en un tiempo determinado: saben con preferencia á otros prácticos, y notan los atunes que van entrando en los sitios que les tienen preparados para que no escapen. Y como tienen la reputación bien sentada de ser ellos los mas diestros de la costa, tambien son ellos los escogidos para tender las ocho almadrabas que hay desde Tortosa hasta Cartagena.

Junto a esta especialización, otras circunstancias como las ordenanzas del mar de 1760 que declaraban la pesca libre y franca en cualquier provincia del reino o la disminución de la actividad pirática —que cesó con la ocupación francesa de Argel en 1830 - permitieron a los técnicos benidormenses expandir su influencia por el Mediterráneo y, especialmente, por Andalucía, calando 54 almadrabas desde Sicilia hasta Marruecos (Oliver 1982: 222-224; Pérez 1987: 1). Fue a partir de finales del siglo XVIII que se empiezan a contratar, en las pesquerías andaluzas, marineros y capitanes valencianos y portugueses expertos en la almadraba de buche.

Estas explotaciones pesqueras seguían en decadencia en la costa andaluza durante el siglo XIX por problemas económicos como la descapitalización y fragmentación económica y social, especialmente por el gravamen sobre la sal ${ }^{4}$. Estas dificultades tuvieron dos efectos en el mundo almadrabero: La primera es que permitió el desarrollo de las empresas y almadrabas portuguesas; y, la segunda, que se pusieron en marcha pesquerías en el norte de África y en el litoral atlántico septentrional. Estas circunstancias propiciaron la imbricación lingüística de marineros y técnicos valencianos, andaluces y portugueses. A inicios del XX se produce la reducción de instalaciones extractivas y la constitución de un modelo monopolístico como la Anónima Com-

${ }^{4}$ Las referencias sobre la evolución histórica de las almadrabas están tomadas de Florido (2005: 54-65). 
pañía Almadrabera Española y, sobre todo, el Consorcio Nacional Almadrabero que permitieron el predominio de las pesquerías andaluzas (Florido 2013). A partir de los años 50, con la reducción de las capturas y la orientación hacia una economía turística, empiezan a desaparecer las almadrabas más modestas como eran las valencianas. En el último tercio del siglo XX, el calamento de las almadrabas atlánticas andaluzas supervivientes se desarrolla mediante concesiones administrativas. Asimismo desde los años ochenta la economía almadrabera española se orienta al mercado japonés.

\section{SISTEMAS DE CAPTURA}

Para que todo este comercio pudiera llevarse a cabo se necesitó que la cantidad de capturas pasara de ser medio de subsistencia a fuente de excedentes comerciales. Es por esto que la pesca de los túnidos evolucionó desde simples ganchos que arrastraban atunes varados en la arena hasta complejos sistemas de redes como las almadrabas.

El atún no es una presa fácil ni cómoda. La pesca de los grandes peces es una labor dura y peligrosa tanto por las dimensiones del animal como por su fuerza, a lo que hay que añadir el problema que supone la situación de las almadrabas, especialmente las atlánticas. Para salvar estas dificultades, el ingenio humano no dejó de crear y mejorar una serie de artes que facilitaran la captura de los grandes ejemplares a través de una cultura haliéutica que pasó de pueblo a pueblo innovando permanentemente las técnicas de pesca.

Entre estos sistemas, constatados arqueológicamente desde el Neolítico y literariamente en los textos desde los siglos V y IV a. C. (Parona 1919; Ruiz y López 2005), están los croques (o cloques), los aparejos de anzuelos, el bol, el boliche, la jábega, la tunara, los palangres, las redes a la deriva, los artes de cerco e incluso anzuelos dotados de corriente eléctrica entre otras creaciones que no pasaron de un uso local.

Pero sin duda el arte por excelencia es la almadraba, que ha utilizado diversas modalidades. Una de las fundamentales, hasta la aparición de las almadrabas fijas, ha sido la de vista y tiro que Sáñez (1791: I, 13) define así:

La Almadraba de Vista, como la de Conil, que no tiene calamento ó armazón alguna echada ó puesta de firme ó posado en el mar, sino que los barcos, con sus correspondientes redes, se hallan esquifados y prontos para cercar con ellas la pesca que se avista desde una torre [...] avisan con respectivas señales á los mismos barcos apostados: y segun ellas conocen estos el rumbo, dirección ó viage que traen los atunes, y parten á fuerza de remo á calar las redes que tienen en sus bordos cada uno para cercarlos y traerlos ácia tierra, á cuyo efecto sucesivamente echan en la playa los cabos de alár, que cierto número de hombres y muchachos cogen luego, y tirando de ellos, sacan la pesca sobre la arena, en donde la matan y conducen á los saladeros. Por esta segunda acción de tirar la gente para traer á tierra los peces, se les suele aplicar el nombre de Almadraba de tiro.

Este tipo de almadraba evolucionará, a partir del siglo XVI, a un arte fijado al fondo durante toda la temporada con un cuadro o cuerpo central dividido en compartimentos donde se conduce al atún. Este sistema fue una innovación técnica muy productiva que, como hemos dicho, se importó de Sicilia. La tonnara siciliana tuvo una gran expansión a principio del siglo XVII, aunando innovación técnica y lingüística. 
Sirva como ejemplo que, en este proceso, es cuando aparece en catalán la palabra almadrava aplicada al arte pesquero en aguas de la Corona de Aragón, desplazando la voz tonaira que había sido la usada hasta el momento. Un excelente ejemplo de cambio terminológico causado por un avance técnico. Fueron estas almadrabas fijas - con denominaciones como monteleva o buche - las que proporcionaron las mayores capturas excedentarias del atún disminuyendo, además, el peligro y el esfuerzo que hay que realizar para obtener un producto que sería destinado, en su mayor parte, a la salazón.

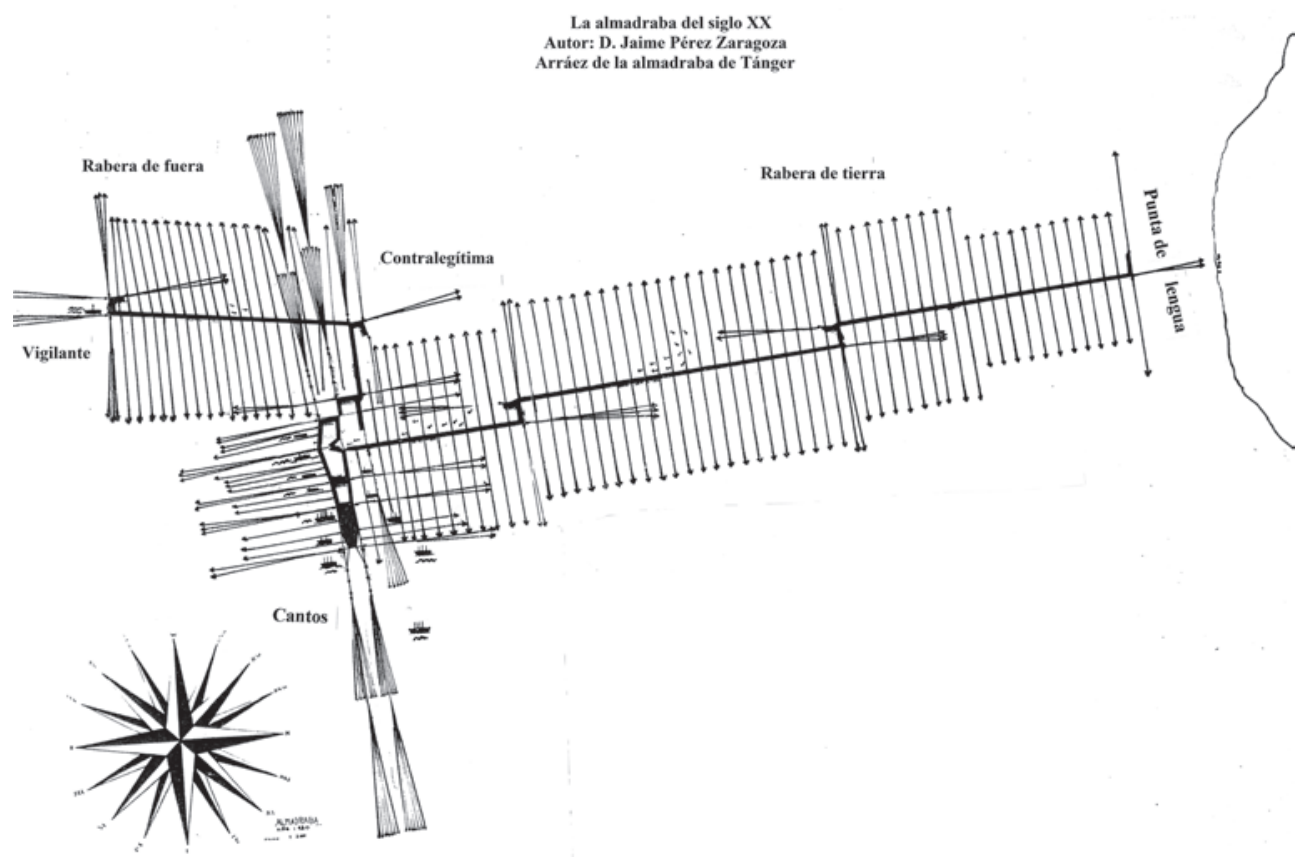

Imagen 2.- La almadraba del siglo XX. Dibujada por Don Jaime Pérez Zaragoza, arráez de la almadraba de Tánger.

\section{IMPORTANCIA COMERCIAL DE LA SALAZÓN}

El porcentaje de carne aprovechable de los atunes como también su facilidad de tratamiento, conservación, transporte y el alto beneficio económico son las circunstancias que han permitido la comercialización del pescado en cantidades masivas desde épocas remotas (Bellón 1926: 5-10; Oliver 1982: 64; Gallart et al. 2005: 23-92; Ruiz y López 2005: 18-23). Hay que tener en cuenta que de cada 100 kilogramos en vivo de atún se pueden extraer 61 kilogramos de carne de primera calidad, 8 kilogramos de carne de inferior calidad y 4 kilogramos de buche e intestinos. Los otros 27 kilogramos — cabeza, espinas y aletas del pez- son consumidas en algunas zonas o usadas 
para fertilizantes agrícolas (Rodríguez 1923: 42). Por tanto, hablamos de grandes ejemplares aprovechables íntegramente. Incluso los ojos, además de poder ser consumidos, también se utilizaban para fabricar jabón y cirios en España y Portugal; o para extraer aceite. De hecho, los túnidos son el grupo de especies marinas más consumidos en el mundo por delante de otros como los gádidos, salmónidos, cupleidos o espáridos (López et al. 2007: 143-149; Florido 2013: 143).

Un fructífero negocio que fue monopolio de la realeza y cedido a la nobleza como privilegio. Ya en tiempos de la conquista cristiana de al-Ándalus, la posesión de las atunaras era un bocado apetecido por los nobles de Aragón y Castilla como explican los estudios históricos sobre el tema (Rodríguez 1923: 41; Guillén 1963: 116; Oliver 1982: 98-129; Ruiz y López 2005: 24-30), situación repetida en Portugal (Rosa 1989: 20), Cerdeña (Mariotti y Pronzati 2003: 39) e Italia (Parona 1919).

Es decir, la importancia del atún nace de su potencial crematístico, con unos beneficios que se sumaban a la venta de la sal, también controlada por la realeza. Un alimento estratégico para la cultura cristiana, sobre todo en Cuaresma, porque el consumo de carne de ganado estaba vetado, convirtiendo la ingesta de atún en una importante fuente de proteínas durante este período sacro. Hay que añadir que las partes menos valoradas del atún (vísceras, cabezas, puntas de barriga, etc.) eran productos con un precio asequible a las clases populares —o distribuidos como remuneracióny, por ello, han constituido uno de los pilares alimenticios de la población mediterránea de escasos recursos económicos como estudia Florido (2013: 142-144). Martínez (1912: 33-36) nos dejó escrita la dieta tradicional en Altea (Alicante) donde el alto consumo de salazón explica por qué gran parte de las capturas atlánticas se dirigían a los mercados valencianos y catalanes:

La base de l'alimentació es el peix, la saladura, arròs y llegums, apart del pa [...] Per lo general no's consumix carn més que per malalts y els pudients; quant no hi ha peix fa tot el gasto la saladura, la que's consumix en grans cantitats, particularment la mèlva, cavalla, bull (ventre de tonyina), budellet (les tripes de la mateixa), sangajo (els desperdissis, tot lo més roín de la tonyina), anjòva de sardina, y els més pudients d'aladròch; aixina com bonyitol, bacallar, òu de tonyina y moixama.

Un consumo que podemos hacer extensible a casi toda la costa del Mediterráneo dando lugar a una firme actividad comercial e industrial. Además su disponibilidad propició una cocina tradicional basada en productos salados, especialmente entre las gentes humildes como describe Barral (1985: 53) de L'Ametlla de Mar (Tarragona):

[...] (l'espineta de tonyina) serveix per a un guisat molt fort, més aviat d'hivern, que es fa amb patates i altres vegetals i de vegades amb cargols [...] És un menjar mariner que no ha passat a la cuina burgesa. Era, de fet, un matafam dels pobres.

Con mucho acierto Chiaramonte (2006: 7) califica il tonno de "salvatore di tante bochhe negli ultimi tre o quattro millenni».

Que las salazones estuvieran en la base alimenticia de las clases populares de Cataluña y el Reino de Valencia, y que fuera un territorio con numerosa población árabe dedicada a este trabajo, explican por qué las técnicas valencianas adquirieron un papel primordial en el período medieval: 
A principio del siglo XVI, la diferencia de salario era de medio real, pero a finales de siglo, los salarios se habían igualado en real y medio. Dos y medio ganaban los que salaban "a la valenciana". Envasaban únicamente en botas, no admitiendo mujeres 5 .

Eran unos productos de gran consumo que en ciertos períodos no se elaboraban en cantidad suficiente para atender la demanda existente en la Corona de Aragón, por lo que se tenía que recurrir a la importación. De hecho, la casa de Medina Sidonia tenía Valencia y Barcelona como puertos principales de exportación en el siglo XVI, aunque también sus géneros llegaban a Italia y Flandes. Igualmente se importó mercancía desde Cerdeña y Sicilia, otra circunstancia que facilitó el intercambio lingüístico a través de mercaderes, artesanos y productos. Era la Valencia que vivió una época de esplendor demográfico en aquel tiempo como indica Oliver (1982: 108-109):

Durante todo el s. XVI, el Reino de Valencia, con sus $23.200 \mathrm{~km}^{2}$, llegó a tener más de medio millón de habitantes, lo que suponía la media de habitantes por kilómetro cuadrado más alta de España y así se mantendría hasta la expulsión de los moriscos a principios del XVII. [...] Se sigue consumiendo pescado salado, tanto el bacalao transportado ahora por Bretones, como el atún traído de Cerdeña.

Así pues, comerciantes de todas las costas mediterráneas se dedicaron al negocio de la salazón, fundamentalmente sicilianos, genoveses y catalanes, quienes reforzaron sus posiciones, particularmente en el siglo XVIII, pero también sardos, vascos, ingleses y flamencos. Es en este siglo, sobre 1723, cuando fomentadores catalanes llevaron nuevas técnicas y cultura a las almadrabas onubenses dando lugar a la fundación de La Higuerita, actual Isla Cristina (López Márquez 2006: 33):

En torno al año de 1723, comenzaron a llegar los traficantes de la salazón catalanes a las costas próximas a la desembocadura del río Guadiana en busca de sardina [...] En la temporada pesquera de 1756, como consecuencia del desastroso terremoto acontecido el año anterior, algunos catalanes supervivientes de los que se hallaban dispersos por las playas decidieron agruparse en un lugar más apropiado, y fundaron así La Higuerita.

Así pues tenemos en el siglo XVIII un punto de encuentro formado por Isla Cristina, Ayamonte y Montegordo — ampliado posteriormente con la fundación del municipio portugués de Villa Real de San Antonio- donde castellano, portugués, italiano y catalán volverían a participar en la construcción de un lenguaje atunero común.

Por otra parte, en el siglo XIX, entraron en juego nuevos procesos de conservación del pescado como la conserva en lata, que ya se aplicaba en Italia en 1868 (Rodríguez 1923: 42; Mariotti y Pronzati 2003: 22). Un sistema de conservación inventado por el francés Nicolás Appert y aprovechado, especialmente, por familias genovesas como los Parodi que lo introdujeron en Portugal en 1879 (Rosa 1989: 14):

[...] em 1879, surgiu no Algarve, mais concretamente em Vila Real de Santo António, a primeira fábrica de conserva de atum, montada por A. Parodi, industrial italiano. Daí em diante e nos sessenta anos seguintes, a indústria da conserva cresceu enormemente no país e, em 1884, existiam já 18 unidades. Mais tarde, em, 1886, este número passou para 66, atingindo, em 1945, as 246 fábricas.

\footnotetext{
${ }^{5}$ http://www.fcmedinasidonia.com/1historias3.htm, página consultada el 4 de octubre de 2002. Página actualmente inactiva.
} 
Esta novedad tecnológica no solo influyó en el mundo pesquero y comercial sino que también en el lingüístico y reforzó la presencia del portugués como lengua exportadora de terminología. Novedades tecnológicas que también fueron aprovechadas por familias valencianas para expandir su negocio conservero por Andalucía, Ceuta y Canarias como la empresa Lloret y Llinares, o familias catalanas por Galicia como los Romaní (Llorca Baus 1994: 97; Romaní 1998).

En resumen, el altísimo consumo de salazón fue el pilar sobre el cual se creó un lucrativo negocio por todo el Mediterráneo. Esto ocasionó que los comerciantes transportaran el atún y sus derivados de puerto en puerto pero también de lengua en lengua. Fue (y es) esta presencia de productos en constante consumo y migración la que mantiene el léxico del atún en permanente vitalidad e intercambio.

\section{EL LÉXICO DEL ATÚN}

\subsection{ATÚN Y TÚNIDOS: DENOMINACIONES}

El nombre castellano del Thunnus thynnus es atún. Ya de por sí este vocablo es ejemplo de la itinerancia que caracteriza el léxico de los túnidos. El origen lingüístico de atún coincide con la situación geográfica de los primeros asentamientos dedicados a su pesca: Grecia. Es un ictiónimo originado en el griego túvvos de donde pasa al latín thmnnus. Del latín lo toma el árabe -at-tûn que lo transmite, con la prótesis de la $a$ - inicial, al castellano y al portugués: atún y atum respectivamente (Corominas y Pascual 1980: I, 408; Coromines 1995: VIII, 563). Cabe destacar que todas las lenguas han creado la especificación atún de derecho, procedente del Atlántico y que va a desovar, y atún de revés, atún que sale del Mediterráneo después de desovar, por la importancia que este hecho tiene en la calidad de la carne como narraba Palmireno (1569: 65):

Y es así que quando estos peces uienen, son gordos y muy buenos, y luego que han desouado se paran tan flacos, que no son de comer.

Otra característica del atún es el extraordinario desarrollo de la especie que Lotina y Hormaechea (1986: IV, 267) explican desde la biología:

\footnotetext{
Se calcula que a la edad de tres años el atún alcanza un metro, a los diez años aproximadamente los $2 \mathrm{~m}$ y a los 15 años los $2,50 \mathrm{~m}$ de longitud. Después sigue creciendo en edad y longitud, pero no suele pasar mucho de los quince años. Algunos atunes separados de los bandos, que nadan erráticos por las aguas del Océano, suelen alcanzar grandes dimensiones, midiendo normalmente unos $2 \mathrm{~m}$, pero pudiendo alcanzar los $4 \mathrm{~m}$ de longitud y pesos superiores a los 500 y hasta a los 800 kilos.
}

Estas fases de crecimiento se han visto reflejadas en las denominaciones de los almadraberos, por lo que encontramos que el argot atunero posee vocablos diferentes según el tamaño y edad de los ejemplares. Especialmente remarcable es la distinción que vemos en las denominaciones gaditanas y onubenses, las dos zonas principales en capturas. López et al. (2007: 34) reportan los términos atunete (con 5 a 6 
kilos); cachorreta, con un peso aproximado de 6 kilos; albacora, hasta los 12 kilos; atuarro hasta los 50 kilos y atún a partir de los 50 kilos.

En portugués también existe la diferenciación nominal con cuatro términos: atum, más de $110 \mathrm{~kg}$; atuarro entre 100 y $40 \mathrm{~kg}$; albacora entre 35 y $15 \mathrm{~kg}$; cachorreta con menos de $10 \mathrm{~kg}$ (Rosa 1989: 17). Para Italia, Parona (1919: 138 y 256) da las siguientes denominaciones: tonnicello cuando pesa de 20 a 60 kilogramos, tonnocolo o mezzo tonno entre 60 y $100 \mathrm{~kg}$, tonno di corsa o da stellato o barilaro si supera los $200 \mathrm{ki}$ logramos 6 , y tonno vero: "quando supera les 300 libbra". Y, finalmente, vemos que en catalán la distinción se reduce a dos términos: tonyineta si el animal pesa menos de ochenta kilogramos, y tonyina si supera este peso, siendo usada por los almadraberos profesionales la terminología andaluza.

\subsection{Elaboración DEL ATÚN Y SUS DENOMINACIONES}

La elaboración industrial del atún se realizaba en la instalación almadrabera denominada chanca, italianismo que en muchos casos acabó por denominar todos los edificios terrestres de la almadraba (Llorca Ibi 2004) ${ }^{7}$. Estas instalaciones eran auténticos poblados de colonización al lado del mar con una gran repercusión social, económica y demográfica sobre su área de influencia, llegando a constituir núcleos humanos mantenidos hasta la actualidad (Sáñez 1791; Venero de Valera 2005; Bellón 1926: 35; García 2001).

Para la elaboración del atún en las fábricas se seguía un orden estricto en el que cada operario se centraba en una actividad concreta, dividiéndose el conjunto de operarios en grupos de trabajo especializado. Eran procesos donde se valoraban la eficacia y la celeridad porque el período de la temporada coincide con meses calurosos en los que el atún se corrompe fácilmente.

Los términos que encontramos para el corte del atún son descabezar 'quitar la cabeza', escalar 'abrir en canal el atún, descuartizar', ronquear 'partir en cuatro porciones y sacar las vísceras', despellejar 'quitar el pellejo', descargar 'extraer las piezas del atún' y picar 'cortar en trozos'. Cada operación, desde el descabezado hasta el tratamiento del guano, recibe una denominación específica, que son ejemplos de singularidad nominativa a partir del uso de la terminología propia de la actividad.

Por otro lado, encontramos el personal técnico de las chancas andaluzas en Bellón (1926: 53-57). El cargo más importante era el maestro o director de la fábrica que, en algunas de ellas, era italiano o portugués (incidiendo en la terminología empleada). Dentro de los empleados de las chancas hay ocupaciones como ronqueador 'operario que descuartiza el atún y saca sus vísceras' y petero 'encargado de quitar la piel a los

\footnotetext{
${ }^{6}$ No obstante en la p. 256 indica que recibe el nombre de tonno di corsa o da stellato o barilaro si supera los cien kilos.

7 Bellón (1926: 20) describe tres tipos de factoría de atún desde una perspectiva técnica: grandes fábricas (solo trabajan atún), fábricas mixtas (trabajan atún y otras especies) y fabriquines (dedicadas a la salazón).
} 
cuartos del atún y cortarlos en trozos grandes' ${ }^{\prime 8}$. Para la salazón también existen diversas denominaciones específicas de operarios como los de la tabla, estibadores ${ }^{9}$, picadores, tinaleros, maestro de la batería, caldereros, fogoneros, maestras y estibadoras ${ }^{10}$.

Un personal y unas operaciones especializados con la finalidad de sacar el mayor provecho posible de las distintas partes del atún.

\subsection{LAS PARTES DEL ATÚN Y SU LÉXICO ${ }^{11}$}

El atún es un animal que ha sido intensamente observado y estudiado para poder obtener el máximo beneficio. Los pescadores y saladores trabajan todas las partes del atún de una manera u otra. Es por esto que los entrevistados afirmaban que lo único que salía de la chanca sin provecho era la sangre ${ }^{12}$. El uso intenso y secular provoca que cada pieza, tanto externa como interna, reciba un término específico. Unas denominaciones donde se conjugarán factores como el tamaño del pez, la época de captura (de derecho o de revés) o el destino comercial, fundamentalmente porque el ronqueo será distinto.

Los términos de las partes del atún que encontramos son cabeza, tronco, ventresca, cola, aletas y alerones. El tronco a su vez contiene subdivisiones. Unas son tomadas desde un plano perpendicular al eje del atún que pase por el ano ${ }^{13}$ resultando tronco de cola y tronco de cabeza. Y también encontramos cuartos negros - partes superiores- y cuartos blancos - partes inferiores, ventral-. Blanco y negro indican el color de la piel que envuelve los cuartos ${ }^{14}$. Estos cuartos, a grandes rasgos, corresponden a la musculatura epiaxial e hipoaxial respectivamente. El cuarto negro lo forman el lomo negro ${ }^{15}$, la espineta negra y el sangacho. Del lomo negro se descargan dos solomillos,

\footnotetext{
${ }^{8}$ Sáñez (1791, I, 56) reporta el término tradicional cuchilla de Conil: "Cuchillas: son tres hombres diestros y destinados á destrozar los atunes para echar la carne á salar en las Chancas, ó Pilas". Varios entrevistados nos decían que el término usado en las almadrabas andaluzas era alañador, sustantivo posiblemente derivado del verbo portugués alanhar 'Abrir o peixe de alto a baixo para lhe extrair a espinha e a cabeça'. Definición lusa extraída de Tesouro do léxico patrimonial galego e portugués. Página consultada el 15 de septiembre de 2015.

9 Bellón (1926) escribe estibar y sus derivados con -v siguiendo la grafía italiana.

${ }^{10}$ Maestra 'mujer que vigila la estiva o enlatado' y estivadora 'mujer que coloca el atún cocido en las latas' (Bellón 1926: 54-56), son de los pocos ejemplos donde encontramos presencia femenina.

11 Este apartado se realiza a partir de informaciones orales y se completa con Bellón (1926: 67-69) y López et al. (2007: 94-95, 132).

${ }^{12}$ La sangre de los escómbridos contiene altísimos niveles de histamina que provocan intoxicación, vómitos y diarrea (López et al. 2007: 48). Uno de los recuerdos más marcados en la memoria de los almadraberos entrevistados era el olor de sangre de atún que les quedaba en el cuerpo durante meses. Sagarra (1984: 86-87) usa el olor remanente tras un lance como imagen literaria que describe un ambiente primario e inhumano: "La Marí ha anat a la font, ha voltat pel poble olorant l'aire de tonyina sacrificada".

$13 \mathrm{El}$ ano del atún recibe el nombre de chochuelo en Isla Cristina.

${ }^{14}$ Bello (2005: 94) reporta los vocablos medievales atún blanco y atún de badán. Es nuestra opinión que atún blanco corresponde a los actuales cuartos blancos; y atún de badán corresponde al actual cuarto negro o atún de lomo.

15 Bellón (1926: 68) sólo denominaba lomo (o tonno) a la capa muscular externa del cuarto negro. En López et al. (2007: 79) vemos que, actualmente, se llama lomo también al cuarto blanco de los atunes de revés exceptuando la barriga.
} 
el plato, el descargado y la cola negra. El cuarto blanco lo forman el lomo blanco, el sangacho ventral ${ }^{16}$, la parpatana o palpetana ${ }^{17}$ y la espineta blanca. Del lomo blanco sale el tarantelo, el descargamento, la ventresca ${ }^{18}$, la filosa y la cola blanca ${ }^{19}$. Además, Bellón (1926: 66) también reportaba las denominaciones churumbel 'músculo de la aleta pectoral' y carrasquiña 'músculos del espinazo'.

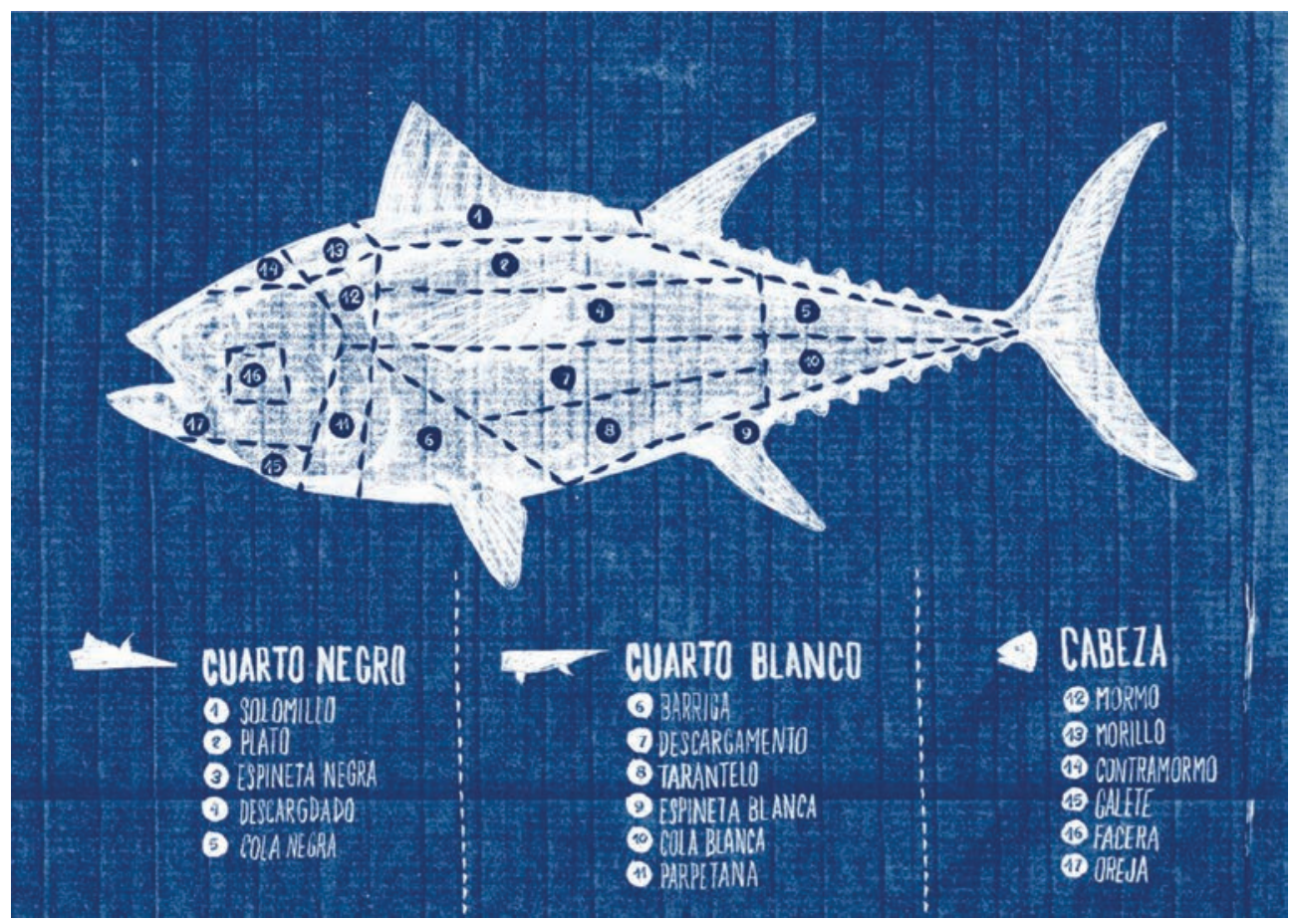

ImAgen 3.- Partes del atún. Tomado con autorización de AVE THUNNUS de David Robles, José Luis Gozálvez y José Antonio López (2015: 77).

Actualmente de la cabeza se aprovechan diversos músculos como los morrillos, mormos y contramormos, la facera y el galete. También contamos con la oreja 'músculo hipobranquial' que contiene la cococha, parte de la oreja que se sitúa entre las mandíbulas; y el ojo, músculo óculomotor. La cabeza era una parte del atún que an-

${ }^{16}$ Bellón (1926: 65) distingue entre sangacho negro 'sangacho del cuarto negro' y sangacho blanco 'sangacho del cuarto blanco'.

${ }^{17}$ Bellón (1926: 66) usa palpetana.

18 Bellón (1926: 66) también recoge para esta pieza las denominaciones de barriga, zorra o toquilla.

${ }^{19}$ Unas denominaciones que cambian entre atunes de derecho y de revés complicando la terminología del atún para los no iniciados: "El atún rojo de revés, que está más delgado, se ronquea de distinta manera: de la cabeza se obtienen las mismas partes que el atún de derecho pero en la parte superior se comercializa como lomo y en la parte inferior solo se distingue la barriga del resto denominado lomo" (López et al. 2007: 78-79). 
tiguamente no se consideraba de gran valor comercial pero actualmente se trabaja al detalle. Estas partes estaban destinadas al consumo familiar principalmente en la zona entre Valencia y Cartagena; y entre la marinería lusa, que generalizó su consumo en la zona sur de Portugal. Finalmente podemos añadir la lengua y el paladar que tienen un consumo muy limitado; y los bigotes, bordes de la parte anteroinferior del aparato opercular. Además encontraremos las agallas o branquias.

Los órganos internos también son tenidos en cuenta en el ronqueo y la salazón. De estos podemos enumerar el buche, el corazón, las tripas, el hígado o asadura, la hueva de grano y la hueva de leche (López et al. 2007: 78, 130-131) ${ }^{20}$.

Finalmente, tenemos que cociendo y prensando los despojos del atún (columnas vertebrales, cabezas, trozos de piel, aletas, etc.) se produce un abono agrícola denominado guano y, antiguamente, el llamado aceite de guano (Bellón 1926: 33; López et al. 2007: 39).

Asimismo, encontramos otras denominaciones en el atún rojo, que no sea de almadraba, porque los ejemplares pequeños no se ronquean sino que se venden frescos como pez de corte. En estos el tronco es la parte principal y recibe la denominación genérica de atún de tronco ${ }^{21}$. Las diferencias nominativas pueden también estar entre las piezas de un atún fresco y de un atún congelado con intercambios semánticos que desorientan a los profanos:

El plato que en este atún se le conoce como tronco ha experimentado una subida el último año en un $25 \%$ en comparación con el precio del tarantelo llamado lomo y no llegando a $6 € / \mathrm{kg}$ (López et al. 2007: 80).

Todas estas denominaciones y su interrelación nos permiten comprender la larga historia del lenguaje del atún donde la concurrencia de diversos factores económicos, gastronómicos, como también de índole relacionada con las técnicas de corte y conservación, inciden profundamente.

\subsection{La SALAZÓN DEL ATÚN Y SU LÉXICO}

El atún es el animal más aprovechado del mar como nos confirman los porcentajes de uso que hemos visto anteriormente. La presentación más directa de los túnidos es el atún en fresco que se encuentra en los mercados, el cual se consumía cocinado o escabechado. Pero de cada parte que hemos señalado se pueden realizar elaboraciones saladas, salazón. Antiguamente, más allá del consumo fresco, la única preparación era el salado hasta que los avances tecnológicos permitieron la conserva en lata. Desde finales del siglo XIX también se consume en conserva (en escabechado o en aceite), sin olvidar el minoritario ahumado del atún (Oliver 1982: 35).

Las partes más aprovechadas del atún han sido el tronco y la ventresca. Históricamente el tronco se ha dedicado a la salazón pero desde la aparición de la industria

\footnotetext{
${ }^{20}$ Bellón (1926: 62) denomina a los testículos, hueva en leche.

${ }^{21}$ Bellón (1926: 65) distingue entre el tronco de cabeza y el tronco de cola según la parte de donde se extrae; y, dentro de cada mitad, tronco de cabeza y de cola del cuarto negro y tronco de cabeza y de cola del cuarto blanco.
} 
conservera se destina mayoritariamente al envasado. No obstante, la salazón más estimada ha sido la parte ventral de donde se extrae la pieza denominada ventresca, barriga o ijar siendo la que se ha mantenido como delicatessen gastronómica en todas las épocas. Plinio, en el libro IX, capítulo XIV, ya indicaba que las mejores piezas son la ijada, la cerviz (el morrillo) y el cuello (el contramormo) (López et al. 2007: 48). Junto a estas piezas, la tradición mediterránea nos ofrece otros productos del atún rojo. Entre los principales destaca la mojama ${ }^{22}$, carne salada y seca que sale del descargado y del descargamento. Otra pieza relevante es el sangacho, músculo rojo oscuro responsable de los desplazamientos constantes y regulares del atún, situado a los lados de la columna vertebral. Era un alimento despreciado que se destinaba, generalmente, a la fabricación de harina de pescado. No obstante, el sangacho salado es tradicional en la gastronomía valenciana, portuguesa y griega (López et al. 2007: 110 y 132). Otros productos como la espineta negra 'parte correspondiente a las aletas y pínnulas dorsales' y la espineta blanca 'pínnulas ventrales' antiguamente se salaban con una parte de carne adherida ${ }^{23}$. También se aprovecha como aperitivo el pellejo 'piel de los cuartos, sobre todo de los lomos blancos y de la ventresca'. Además, los entrevistados hacían mención de las orejas, que se salaban para su conservación pero que se tenían que desalar para su consumo — se ponían a remojo- y se hervían o guisaban.

De los órganos internos el más sobresaliente es la bueva —ovario-, que se sala, prensa y seca. El aprovechamiento — tardío- de los testículos del macho provocó la distinción entre hueva de grano 'ovario' y hueva en (o de) leche 'testículo'24. El intestino, que se sala y se seca. El estómago o buche, vientre del atún, se abre, se limpia, se sala intensamente y se pone a secar. También los entrevistados mencionaban el corazón, que los marineros recibían como recompensa, se salaba y secaba ${ }^{25}$. Y, finalmente, los marineros salaban el hígado del atún que lo usaban para cebar ${ }^{26}$. Asimismo, la industria italiana aprovechaba el hígado para elaborar un aceite medicinal denominado tinnoleum ${ }^{27}$.

Del atún también se pueden extraer tres clases de aceite: el aceite de batería, el aceite de garlanda y el aceite rojo o de guano, dependiendo de los diversos procesos por los que pasa el pescado. Por otra parte, de los restos no comestibles o rechazados del pez, se obtiene un abono denominado guano y harina de pescado.

${ }^{22}$ Bello (2005: 94) reporta el término medieval mojama verde. En nuestra opinión se trata de la pieza salada del atún sin secar.

${ }^{23}$ Actualmente no se suelen aprovechar comercialmente: "Pero es muy difícil conseguirla del rojo pues normalmente no se extraen y solo son consumidas por los trabajadores de la chanca y casi siempre se dedica para harina de pescado" (López et al. 2007: 85-86).

${ }^{24}$ Bellón (1926: 70) afirmaba que no se solían aprovechar. Sí que son de consumo tradicional en la zona valenciana donde existe un término específico que lo designa, lletó, derivado de llet 'leche'. En el castellano de Murcia adaptan este término en la forma letón, circunstancia que afirma la preponderancia de su consumo en la zona valenciana.

25 Bellón (1926: 70) decía que solo se consumía el ventrículo fresco o salado.

26 Chiaramonte (2006: 57) explica que, en Italia, es un órgano con apreciación diversa: "La ghiandola epatica è differentemente apprezzata. Per molti operatori è considerato uno scarto per via del sapore decisamente amaro, per altri ha rappresentato uno spunto culinario interessante".

27 García (2001: 100-101), y Ruiz y López (2005: 172) también apuntan el uso del hígado del atún con finalidades farmacéuticas en España. 
Finalmente, hemos de hacer constar órganos como el cerebro o el páncreas que no suelen aparecer ni en las narraciones de los entrevistados, ni en la bibliografía en general, dada la falta de interés comercial o gastronómico, o porque están englobados en términos generales como guano o ventresca.

\section{ANÁLISIS LINGÜÍSTICO}

El lenguaje del atún es un argot usado por los profesionales dedicados a la captura y procesado de los túnidos, así como por su entorno social más próximo, que cuenta con dos características muy marcadas. La primera es que, mayoritariamente, se trata de un léxico usado por grupos, muchas veces migrantes, que pertenecían a estratos socioeconómicos humildes y discriminados por otros sectores poblacionales, circunstancias que facilitaron la sensación de comunidad que describe García (2001: 26-27). La segunda característica es que el repertorio léxico está formado, en un porcentaje muy significativo, por términos de lenguas diversas muestra del mestizaje humano y cultural de las comunidades almadraberas como también reflejo de la renovación tecnológica y gastronómica del sector. En palabras de Florido (2005: 37):

Se trataba de un paisaje heterogéneo, culturalmente atractivo, sobre todo porque en los sitios de almadraba se daban cita trabajadores de los más diversos puntos y de diversas condiciones sociales.

Algunos términos de este lenguaje se han generalizado por la intervención de actantes sociales diversos en los procesos de comercialización y venta, como también por el uso que hacían los consumidores de las piezas más apreciadas del atún.

Para ilustrar léxicamente el universo almadrabero son significativos sustantivos que aparecen en las descripciones históricas de las pesquerías como brevión, choza, chusma, ramada o venturero, que nos ayudan a contextualizar el paisaje físico y social del mundo atunero. Igualmente, la existencia de un concepto como partes nobles, es decir las más apreciadas y consumidas por las clases altas, frente a las que no lo son (vísceras y otros despojos del atún), son un claro exponente de la estratificada apreciación social que suscitaba la vida de las atunaras ${ }^{28}$.

Otro fenómeno relacionado con esta realidad es que las piezas más consumidas por las clases humildes son denominadas con diminutivos (espineta, galete o carrasquiña), nombres humorísticos (churumbel) o sufijos despectivos (sangacho) que son formas lingüísticas ligadas a registros coloquiales. Añadiremos la utilización de términos expresivos, marcados como vulgares por los diccionarios, como chochuelo para indicar el ano de los túnidos. En cambio, las partes nobles se denominan con sustantivos primitivos, no derivados ni marcados, como ijada y lomo; o con préstamos de connotaciones exquisitas como tarantelo y ventresca.

\footnotetext{
28 "La salazón era consumida por todos. Las clases pudientes de entonces se reservaban el mejor bacalao inglés y la mejor parte del atún para hacer sus guisos como se refleja en un recetario de cocina gandiense de 1905 de la familia Company [...] En cambio, los capellanes, el sangacho, el bonito seco, las sardinas de bota [...] eran para aquellos hogares humildes de escasas pretensiones culinarias" (Gallart et al. 2005: 147).
} 
Dentro del contexto sociocultural, también es significativa la sustitución de términos técnicos por otros coloquiales como indica Bellón (1926: 29):

Una de las instalaciones más importantes de estas fábricas es la de los autoclaves para esterilizar las latas, llamados vulgarmente cocedores.

Por lo que respecta a la movilidad inherente a los grupos humanos participantes en esta actividad, el análisis de su léxico nos aporta esclarecedores testimonios de las lenguas y de los pueblos participantes siendo los más importantes el castellano, el árabe, el portugués, el catalán y el italiano, con unas voces griegas presentes en la terminología de las atunaras que nos remiten a las raíces de la actividad haliéutica. Entre estas formas primigenias encontramos el sustantivo atún (portugués atum), con un largo recorrido mediterráneo desde sus orígenes helénicos hasta su arribada a la península ibérica a través del árabe, como hemos explicado anteriormente. Este mismo fenómeno de migración léxica ocurre con la palabra bol 'arte de pesca, lance' del griego

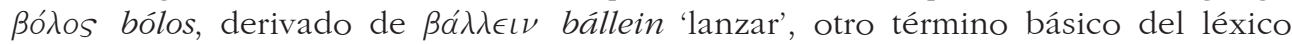
almadrabero que podemos remontar hasta los albores de la pesca. Neologismos, en su día, que fueron incorporados a través de innovaciones tecnológicas pesqueras y que nos hablan de la permanencia cultural y lingüística desde hace milenios.

Un tercer término básico mediterráneo es toñina. Esta forma puramente románica parece proceder del diminutivo *THǓNNİNA en referencia al atún joven como en portugués tonhina y tonbino 'atún pequeño'. También existe la acepción lusa de tonbina 'atún (en general)' como encontramos en catalán actual y en castellano antiguo ${ }^{29}$. Por otra parte, en italiano tonnina es la carne salada del atún (Parona 1919: 256). Además, el ictiónimo ha pasado al árabe marroquí (țnina) desde las lenguas románicas.

Otras voces han sido adjudicadas a herencia mozárabe como el término hispánico bonito y sangacho, este compuesto por una raíz sang-, justificada por el color rojo oscuro del músculo, más el sufijo despectivo -acho común al castellano y al italiano ${ }^{30}$, con la variante fangacho a Santi Petri (García 2001: 101-102).

Por lo que respecta a Andalucía, el lenguaje almadrabero toma como base el castellano con una terminología repleta de términos específicos de la almadraba como bosque 'colgadero del pescado' (italiano bosco); o con acepciones propias de la salazón y, en buena parte, restringidos a un área andaluza, por ejemplo, churumbel 'músculo de la aleta pectoral', espumerío 'espuma por los saltos del atún', miar 'adjudicarse la subasta gritando mío'... Dado el carácter mayormente argótico de estos términos, muchos de ellos no se encuentran en los diccionarios generales. Queremos destacar el sustantivo matanza 'acción de copejar' que se ha extendido por las lenguas mediterráneas como palabra simbólica, cuasi litúrgica, sobre todo en italiano y francés ${ }^{31}$.

Ahora bien, el dominio castellano se realizó sobre un territorio de lengua semítica $\mathrm{y}$, como hemos visto, sobre un estrato social donde predominaban las clases subalter-

${ }^{29}$ El Diccionario de la Real Academia Española de la Lengua (DRAE) señala toñina como voz viva en Andalucía, pero que los entrevistados no lo tenían por un término actualmente existente en castellano. Disponible en: <http://dle.rae.es/>. Fecha de acceso: 27 feb. 2017.

${ }^{30}$ DCECH, V, 151; DECLC, II, 89-91. El DRAE considera sangacho término dialectal derivado de sangue. Disponible en: <http://dle.rae.es/>. Fecha de acceso: 27 feb. 2017.

${ }^{31}$ Para un estudio completo del término matanza y sus implicaciones ver Toso (2012b). 
nas entre las cuales se encontraban los pescadores arabófonos. Bello (2005: 84) reporta una cita del siglo XV donde se constata que sobre el $25 \%$ de los trabajadores eran árabes:

Entre las partidas correspondientes a 1486 se encuentra una amplia relación de los pagos efectuados a más de sesenta personas, a las que hay que añadir los veintidós trabajadores moros.

Esta presencia propició el traspaso lexical del árabe al castellano como vemos en palabras fundamentales de la pesca del atún como jábega 'almadraba de tiro' o almadraba 'arte de pesca para el atún' del árabe hispánico almadrába 'lugar donde se golpea', junto con otras como albacora, bacoreta, badán, botarga, escabeche o mojama. La influencia de los arabismos fue tan intensa que voces como atún o arráez arrinconaron los términos románicos con los que entraron en concurrencia, en este caso toñina y capitán de la almadraba. En este conjunto, uno de los términos atuneros más significativos es mojama, que se ha extendido a todas las lenguas mediterráneas. Procede del árabe mušámma' 'hecho como carne momia' y está integrado en todas las lenguas almadraberas mediante adaptación fonética: mosciame en italiano, moixama en catalán y moxama en portugués. Otro arabismo triunfante es botarga que existía en el castellano del siglo XVII paralelo al italiano bottarga (y buttagra), occitano boutargo, francés boutargue e inglés botargo. La etimología procede del árabe buṭārikh

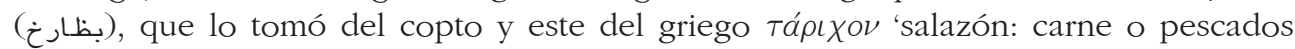
salados' (v. DCECH y Devoto 1992).

Otra fuente esencial para el léxico del atún es el italiano. La presencia de sicilianos y genoveses dedicados al atún en territorio hispánico debió de ser muy temprana; de hecho se remonta documentalmente al siglo XIV en Portugal (Rosa 1989: 20). Asimismo, históricamente, buena parte de la producción se ha destinado al mercado itálico. En referencia a la fuerza de penetración de italianismos, creemos muy significativo que Bellón (1926: 68 y 70) use la voz tonno — con connotaciones positivas- para referirse al lomo del atún, parte esencial de la conserva en aceite. Una palabra que se tomaría de los comerciantes y de los maestros (directores) de las fábricas que, en buena parte, eran italianos (Bellón 1926: 54). Otros términos como tarantelo también provienen de la gastronomía italiana relacionando la pieza del atún con la región de Taranto como marca de prestigio (Parona 1919: 217). Asimismo, la palabra chanca nos muestra el camino que, desde Italia hasta Galicia, realizaban los términos relacionados con el atún y la almadraba (Llorca Ibi 2004). También cabe reseñar el verbo ronquear. Generalmente se tiene este verbo por una voz onomatopéyica del corte del atún (DRAE; Robles et al. 2015: 76). Es nuestra opinión que se trata de una adaptación del verbo italiano roncare "l'atto delle prime incisioni longitudinali che si fa sul corpo del tonno" (Parona 1919: 254). De ronquear deriva el sustantivo ronqueador, que desplazó al término castellano cuchilla. Asimismo términos como bordonal 'tercer departamento de la almadraba' (Toso 2012a: 218-219), paral 'madero para deslizar la embarcación' y su derivado paralero 'operario de la almadraba' son genovesismos (DCECH).

El catalán también realizó su aportación no solo con la presencia continua de comerciantes, sino que hubo significativos asentamientos de catalanohablantes en la costa andaluza y gallega, llegando a influir en algunos procesos de la salazón. Recordemos 
que, según los documentos de la casa de Medina Sidonia del siglo XVI, la salazón "a la valenciana" era mejor gratificada. También se dio una presencia importante de pobladores catalanes en las costas de Huelva, zona comercial estratégica porque servía de puente entre Portugal y España. Un punto clave para estas relaciones fue La Higuerilla, actualmente denominada Isla Cristina, fundada por catalanes para el comercio del atún (Ruiz y López 2005). La aportación lingüística de valencianos y catalanes está presente tanto en el léxico de la almadraba como en el del atún. En la pesquería tenemos palabras, muchas adaptadas fonéticamente, como cloque $<$ croque $<$ croc, blanca < branca, copejar y copejador. Por lo que respecta a la anatomía del atún contamos con ventresca, filosa y, posiblemente, galete < gallet. Y, en la salazón, encontramos los catalanismos garlanda y aceite de garlanda. Otros catalanismos son términos presentes en Murcia como letón, denominado hueva de leche en Andalucía; y zorra, ultracorrección por sorra 'atún de ijada', y a su vez arabismo en el catalán. En este punto, cabe reseñar la función del catalán como transmisor de voces árabes, italianas y griegas al castellano como bacoreta, bol, boliche, chanca, paral, etc.

Finalmente, el portugués vemos que ha influido con fuerza desde el siglo XIX, especialmente en referencia a denominaciones de músculos de la cabeza del pez: mormo, contramormo y facera son los tres términos más significativos. El motivo de esta aportación es la preponderancia de las industrias lusas en el siglo XIX durante épocas de crisis en las almadrabas andaluzas, la presencia de maestros portugueses en las fábricas de salazón y el reclutamiento de personal portugués para las almadrabas a finales del siglo XIX y primeras décadas del siglo XX. Hay que tener en cuenta que, según los entrevistados, parte del salario de los marineros lusos eran las cabezas del atún, una pieza descartada para la gastronomía y la lengua de los españoles. Sin embargo, los marineros portugueses sí que aprovechaban los músculos de la cabeza de donde castellano y catalán tomaron las denominaciones mormo, contramormo y facera. Otras aportaciones lusas son alañar, bichero, carrasquiña, escalar y pandullo.

\section{CONCLUSIÓN}

Vistos y analizados la historia, contexto y composición del léxico de los túnidos, podemos concluir que el lenguaje del atún es un argot común de los pueblos costeros que se han dedicado a la captura y procesamiento de estos seres marinos, y que ha llegado a convertirse en un símbolo distintivo de la cultura mediterránea. Sus características más significativas se centran tanto en la singularidad sociolaboral de las comunidades almadraberas - grupo secularmente discriminado pero también cohesionado-, como en el alto grado de mestizaje verbal fruto de la intervención de diferentes grupos lingüísticos en su formación.

Como síntesis de su génesis y expansión diremos que, aunque todos los pueblos mediterráneos pescaron el atún (Opiano 1990: 271), fueron los griegos quienes conformaron el léxico del pez y su captura. Voces que nos han llegado hasta hoy sumando términos a la base que constituye cada lengua románica. Palabras como atún, bol, boliche o botarga forman parte de los helenismos del castellano y otros idiomas que desde el mar Egeo se exportaron a occidente dando fe de la antigua habla marina. Posteriormente, fueron los musulmanes quienes tomaron el testigo mayor de esta 
actividad, integrando y transmitiendo vocabulario griego, como atún o botarga, y añadiendo términos que expresaban innovaciones léxicas en la captura de túnidos y sus salazones como albacora, almadraba, arráez, escabeche, jábega o mojama. Con la conquista de al-Ándalus y, sobre todo, con la ocupación de zonas almadraberas, las lenguas románicas recibieron una gran influencia arábiga justificada por la nutrida presencia de empleados arabófonos en la pesca. Hemos visto que en listas del siglo XV suponían sobre el $25 \%$ de los trabajadores, porcentajes que serían mayores en los siglos anteriores con la influencia lingüística que esto supone.

En este contexto y sobre todo, a partir de la implantación de la almadraba fija de origen siciliano a finales del siglo XVI, se inicia un estrecho proceso de colaboración entre comunidades marítimas y comerciantes de lenguas románicas que incorporan términos para designar nuevas técnicas de pesca o procesado del pez como chanca, paralero y tarantelo. Sustantivos que los marineros y mercaderes itálicos - especialmente genoveses - traen a la península ibérica. Asimismo, catalanes y valencianos participarán en los procesos de la industria del atún, asentándose temporal o definitivamente en territorios diversos, especialmente en Cádiz y Huelva, aportando léxico al lenguaje del atún como bacoreta, filosa, garlanda, letón o ventresca. Unas aportaciones centradas tanto en la técnica del siglo XVI denominada "salar a la valenciana" como por la preponderancia de los técnicos benidormenses desde el siglo XVIII. Igualmente, hemos constatado que la presencia de técnicos y marineros lusos, especialmente desde finales del siglo XIX, tuvo repercusiones lingüísticas. Algunas circunstancias - como innovaciones en las puertas de la almadraba- aportaron vocabulario al castellano y al catalán como endiche 'puerta triangular en la boca del arte' (Llorca Ibi 2008: 140-142); y otras de carácter alimentario, como el aprovechamiento de la cabeza del atún, generalizaron las denominaciones contramormo, facera y mormo. A su vez, la preponderancia de las almadrabas andaluzas provocó la entrada de castellanismos en otras lenguas como buche en catalán, matanza en italiano y francés (Liauzu 1972: 78; Toso 2012a: 216, 2012b), atuarro y cachorreta entre los profesionales valencianos o la aportación al inglés actual de préstamos tan significativos como moja$m a$, a consecuencia del turismo gastronómico.

Así pues, constatamos que este lenguaje ha seguido un constante proceso elaborativo y renovador acorde a la lenta evolución de sus técnicas. Técnicas que se vieron intensamente modificadas por tres hitos fundamentales: la innovación en el diseño y calado de la almadraba del siglo XVI; los nuevos sistemas de conserva aparecidos en el siglo XIX; y la eclosión de la cultura gastronómica del atún que tiene lugar desde finales de siglo XX. Estas circunstancias aceleraron la entrada de nueva terminología para definir aquello que almadraberos, salazoneros, gourmets y biólogos necesitaban designar enriqueciendo el vocabulario preexistente. Estamos convencidos de que un estudio más profundo del léxico atunero, del que aquí hemos efectuado una completa recopilación, nos proporcionará un apasionante testimonio de las lenguas y la cultura mediterráneas, también atlánticas, que han construido el lenguaje milenario de estos peces míticos. Un patrimonio vivo pero frágil por las circunstancias desfavorables que sufre el atún rojo, fuente de la cultura almadrabera y atunera, en los tiempos presentes. 


\section{BIBLIOGRAFIA CITADA}

Abulafia, David. 2013. El gran mar. Una historia bumana del Mediterráneo. Barcelona: Crítica. Barral, Carlos. 1985. Pel car de fora. Catalunya des del Mar. Barcelona: Edicions 62.

Bello, Juan M. 2005. "Almadrabas andaluzas a finales de la Edad Media. Nuevos datos para su estudio". Historia, instituciones, documentos 32: 81-114.

Bellón, Luis. 1926. La industria del atún en España. Madrid: Ministerio de Marina.

Cano, Maria Antònia. 1993. "La saladura i els seus noms". Quaderns de migjorn 1: 33-36.

Cavanilles, Antonio J. 1795. Observaciones sobre la bistoria natural, geografia, agricultura, población y frutos del Reyno de Valencia. Madrid: Imprenta Real.

Chiaramonte, Carmelo. 2006. A tutto tonno. Lodi: Bibliotheca culinaria.

Coromines, Joan y José A. Pascual. 1980. Diccionario Crítico Etimológico Castellano e Hispánico. Madrid: Editorial Gredos.

Coromines, Joan. 1995. Diccionari Etimologic i Complementari de la Llengua Catalana. Barcelona: Curial Edicions Catalanes.

Devoto, Giacomo. 1992. Avviamento alla etimologia italiana. Florencia: Felice le Monnier.

Florido, David. 2003. "La almadraba como sistema cultural de pesca". Boletín del Instituto Andaluz del Patrimonio Histórico 44: 65-71.

Florido, David. 2005. Evolución histórica y cultural de las almadrabas en el litoral atlántico meridional (siglos XVI-XX). Palamós: Càtedra d'Estudis Marítims.

Florido, David. 2013. "Las almadrabas andaluzas bajo el consorcio nacional almadrabero (1928-1971)". Sémata. Ciencias Sociais e Humanidades 25: 117-151.

Fundación Medina Sidonia. "Historias". <http://www.fcmedinasidonia.com/1historias3.htm>. Fecha de acceso: 4 de octubre de 2002. Página actualmente inactiva.

Gallart, Lorena, Roberto Escriche y Pedro Fito. 2005. La salazón de pescado, una tradición en la dieta mediterránea. Valencia: Universidad Politécnica de Valencia.

García, Miguel Ángel. 2001. El pan y los peces. Santi Petri en la memoria. Chiclana: Ayuntamiento de Chiclana.

Guillén, Julio F. 1963. El lenguaje marinero. Madrid: Real Academia Española.

Liauzu, Claude. 1972. "La pêche et les pêcheurs de thon en Tunisie dans les années 1930". Revue de l'Occident musulman et de la Méditerranée 12: 69-91.

Llorca Baus, Carlos. 1994. Historia marinera de Benidorm. Benidorm: Ayuntamiento de Benidorm. Llorca Baus, Carlos y Jorge Norberto. 1988. Almadraba, salazón y cocina. Alicante: Such Serra, S.C.V.

Llorca Ibi, Francesc Xavier. 2004. "Xanca, chanca: un italianisme del català i de l'espanyol". Estudis de Llengua i Literatura Catalanes / XLVIII. Miscel-lània Joan Veny 4: 157-166. Barcelona: Publicacions de l'Abadia de Montserrat.

Llorca Ibi, Francesc Xavier. 2008. Llengua d'arraix. La parla almadravera valenciana. Valencia: Acadèmia Valenciana de la Llengua.

López, Antonio, Manuel Blasco, Vicente Climent, Fernando J. Fernández, Federico Martínez, Álvaro Pérez, Juan Manuel Ruiz y Damián Sánchez. 2007. El atún y la alimentación mediterránea. Málaga: Junta de Andalucía.

López Márquez, Vicente. 2006. Isla Cristina. Por los caminos de la historia. Punta Umbría: Diputación de Huelva / Ayuntamiento de Isla Cristina.

Lotina, Roberto y Mario de Hormaechea. 1986. Peces de mar y río. Bilbao: Urmo S.A. de Ediciones. Mariotti, Lilla y Virgilio Pronzati. 2003. Il tonno. Le tonnare che parlano genovese. Génova: Il Golfo.

Martínez, Francesc. 1912. Folklore Valencià. Coses de la meua terra (primera tanda). Valencia: Establecimiento tipográfico de Manuel Pau.

Mederos, Alfredo. 2007. "Los atunes de Gadir". Gerión. Revista de Historia Antigua. Vol. extra: 173-195.

Oliver, Manuel. 1982. Almadrabas de la costa alicantina. Alicante: Universidad de Alicante.

Opiano. 1990. De la caza. De la pesca. Madrid: Editorial Gredos.

Palmireno, Juan L. 1569. Vocabulario del humanista. Valencia: Typographia Petri à Huete.

Parona, Corrado. 1919. Il tonno e la sua pesca. Venecia: Premiate Officine Graphiche Carlo Ferrari.

Pérez, Jaime. 1987. La almadraba. Texto mecanografiado cedido por el autor, arráez de la almadraba de Tánger. 
Robles, David, José Luis Gozálvez y José Antonio López. 2015. Ave thunnus. Huelva: Diputación de Huelva.

Rodríguez, Benigno. 1923. Diccionario de arte de pesca de España y sus posesiones. Madrid: Sucesores de Rivadeneyra (S.A.).

Romaní, Arturo. 1998. Una industria salazonera catalana en Galicia. Origen, apogeo y ocaso. A Coruña: Xunta de Galicia.

Rosa, Luís F. 1989. A pesca do atum no Algarve. Algarve: Parque Natural da Ria Formosa y Direcção Geral das Pescas.

Ruiz, Juan Manuel y José A. López. 2005. La almadraba de Nueva Umbría. Huelva: Diputación de Huelva.

Sagarra, Josep Maria de. 1984. All i salobre. Barcelona: Edicions Proa.

Sáñez, Antonio. 1791. Diccionario de los artes de la pesca nacional. Madrid: Imprenta de D. Antonio de Sancha.

Tesouro do léxico patrimonial galego e portugués. Disponible en: <http://ilg.usc.es/Tesouro/pt/>. Fecha de acceso: 27 feb. 2017.

Toso, Fiorenzo. 2012a. „Il lessico storico delle tonnare: Alcune riflessioni”. Bollettino Centro di Studi Filologici e Linguistici Siciliani 23: 211-223.

Toso, Fiorenzo. 2012b. "Mattanza". Lingua Nostra 3-4: 113-120.

Venero, Baltasar. 2005. Visita senyorial a l'estat de Sogorb (1765) i al marquesat de Dénia (1766). Valencia: Universidad de Valencia.

Fecha de recepción: 11 de diciembre de 2015

Fecha de aprobación: 10 de agosto de 2016 